\title{
A Mobile Health Coaching Intervention for Controlling Hypertension: Single-Arm Pilot Pre-Post Study
}

Himali Weerahandi ${ }^{1,2}$, MD, MPH; Soaptarshi Paul ${ }^{2}$, BA; Lisa M Quintiliani ${ }^{3}$, PhD; Sara Chokshi ${ }^{2}$, DrPH; Devin M Mann $^{4,5}$, MD, MS

\footnotetext{
${ }^{1}$ Division of General Internal Medicine and Clinical Innovation, Department of Medicine, NYU Grossman School of Medicine, New York, NY, United States

${ }^{2}$ Department of Population Health, NYU Grossman School of Medicine, New York, NY, United States

${ }^{3}$ Section of General Internal Medicine, Department of Medicine, Boston University School of Medicine, Boston, MA, United States

${ }^{4}$ Department of Medicine, NYU Grossman School of Medicine, New York, NY, United States

${ }^{5}$ Medical Center Information Technology, NYU Langone Health, New York, NY, United States
}

Corresponding Author:

Devin M Mann, MD, MS

Department of Medicine

NYU Grossman School of Medicine

227 East 30th St, 6th Fl

New York, NY, 10016

United States

Phone: 12122638313

Email: devin.mann@nyulangone.org

\section{Abstract}

Background: The seminal Dietary Approaches to Stopping Hypertension (DASH) study demonstrated the effectiveness of diet to control hypertension; however, the effective implementation and dissemination of its principles have been limited.

Objective: This study aimed to determine the feasibility and effectiveness of a DASH mobile health intervention. We hypothesized that combining Bluetooth-enabled data collection, social networks, and a human coach with a smartphone DASH app (DASH Mobile) would be an effective medium for the delivery of the DASH program.

Methods: We conducted a single-arm pilot study from August 2015 through August 2016, using a pre-post evaluation design to evaluate the feasibility and preliminary effectiveness of a smartphone version of DASH that incorporated a human health coach. Participants were recruited both online and offline.

Results: A total of 17 patients participated in this study; they had a mean age of 59 years (SD 6) and 10 (60\%) were women. Participants were engaged with the app; in the 120 days of the study, the mean number of logged blood pressure measurements was 63 (SD 46), the mean number of recorded weight measurements was 52 (SD 45), and participants recorded a mean of 55 step counts (SD 36). Coaching phone calls had a high completion rate (74/102, 73\%). The mean number of servings documented per patient for the dietary assessment was 709 (SD 541), and patients set a mean number of 5 (SD 2) goals. Mean systolic and diastolic blood pressure, heart rate, weight, body mass index, and step count did not significantly change over time $(P>.10$ for all parameters).

Conclusions: In this pilot study, we found that participants were engaged with an interactive mobile app that promoted healthy behaviors to treat hypertension. We did not find a difference in the physiological outcomes, but were underpowered to identify such changes.

(JMIR Form Res 2020;4(5):e13989) doi: 10.2196/13989

\section{KEYWORDS}

eHealth; mobile; telemedicine 


\section{Introduction}

By 2030, hypertension is expected to affect $41.4 \%$ of American adults [1]. However, blood pressure remains insufficiently controlled in almost half of patient cases [2]. The enormous burden of hypertension creates a need for effective interventions with minimal patient burden to encourage successful behavior change. The seminal Dietary Approaches to Stopping Hypertension (DASH) study, published 20 years ago, demonstrated effective control of hypertension through diet [3]. Since then, DASH has been implemented in clinical settings with limited success, partly due to the original intervention design that required substantial in-person participation [4].

DASH for Health, a web-based version of the program, was developed in 2008 to combine the success of the DASH dietary approach of controlling hypertension with evidence-based lifestyle changes (eg, physical activity) and novel internet delivery, thereby reducing the burden of DASH's original in-person design [5]. DASH for Health has been shown to be effective in hypertension management for those who stay engaged with the program for an extended period [5]; however, web-based interventions are still affected by severe drops in patient utilization after the initial weeks of intervention participation [6]. Mobile versions of DASH have been developed but relied on self-reporting for measures of blood pressure, weight, and physical activity, which increase patient burden and may not be accurate [7]. To overcome these limitations, we developed DASH Mobile, a mobile platform that leveraged smartphone technology with Bluetooth-enabled devices, along with human coaching, to facilitate behavior changes.

The widespread use of smartphones among all sociodemographic groups presents a disruptive opportunity to deliver a more accessible version of DASH while increasing patient adherence to the program [8]. By automatically collecting data outside of the clinic and delivering real-time, personalized messaging to each user, smartphone technology minimizes patient burden while creating a positive feedback loop for behavior change.

Our strategy was to adapt DASH to a smartphone-based platform (DASH Mobile) that leveraged automatic data collection with behavior change support from a human coach to replicate the success of DASH in a less burdensome digital context. The purpose of this study was to evaluate the feasibility and potential clinical effectiveness of DASH Mobile, including its effects on engagement (use and acceptability), physiological (blood pressure), and behavioral (diet and physical activity) outcomes.

\section{Methods}

\section{Study Design}

This was a single-arm pilot study conducted from August 2015 through August 2016 with a pre-post evaluation design to evaluate the feasibility and preliminary effectiveness of a smartphone version of DASH that incorporated health coaching. This study was approved by the Boston University Medical Campus Institutional Review Board.

\section{Recruitment and Participants}

Participants were recruited from the greater Boston area via recruitment materials in the local paper and research registry, using an opt-in paradigm. In addition, emails with information about the study were sent to those deemed eligible from Boston University's research volunteer registry. Participants were eligible if they were aged 18-65 years, owned an iOS or Android smartphone with a data plan, were English speaking, were currently taking hypertension medication, or had a diagnosis of prehypertension or Stage 1 hypertension, and were able to give informed consent. Prehypertension was defined as a systolic blood pressure of 120-139 mm Hg, and Stage 1 hypertension was defined as a systolic blood pressure of 150-160 mm Hg for adults aged $\geq 60$ years, $140-160 \mathrm{~mm} \mathrm{Hg}$ for patients with diabetes or chronic kidney disease, or 140-160 mm Hg for all others.

Participants were excluded if they were pregnant or nursing, held a terminal diagnosis, had a diagnosis of secondary hypertension, were unable to easily navigate apps on their smartphone; their baseline blood pressure was in the normal range without blood pressure medication; or they had any contraindications to physical activity. We also excluded patients with medical conditions including dementia, active cancer, or anorexia.

A research assistant obtained informed consent, including HIPPA authorization, from interested participants. The mobile app was then loaded onto the participant's smartphone, and behavior-tracking devices (pedometer, scale, blood pressure cuff) were synced.

\section{Intervention}

We have previously described the development of DASH Mobile [9]. The intervention consisted of a smartphone app to track diet, blood pressure, weight, and physical activity daily, combined with a human coach. During the introductory training session with the DASH health coach, participants were taught how to use the app. The home screen of the app defaults to the current day, where participants self-tracked their diet using a novel, simplified data entry tool based on the DASH portions-based approach to dietary intake (Figure 1). At the bottom of the screen, participants could navigate to any of several tabs: Progress, where they could view all tracked behavior, including diet, blood pressure, weight, and steps; Goal, where editable active and achieved goals were listed (Figure 2); Chat, where participants could communicate with their coach (Figure 3); and Education, which linked to DASH-related resources.

Participants were instructed to track other data several times a day via the wireless devices provided. Bluetooth-enabled wireless sensors (iHealth Labs) from these devices transmitted data for blood pressure, weight, and physical activity to the app. Syncing of data occurred manually when the app was opened; data were uploaded to a web-based coaching portal for patients and the health coach to view the participants' progress. All information transmitted between the phone app and the server was encrypted. 
Figure 1. Simplified data entry tool based on the DASH portions-based approach to dietary intake.

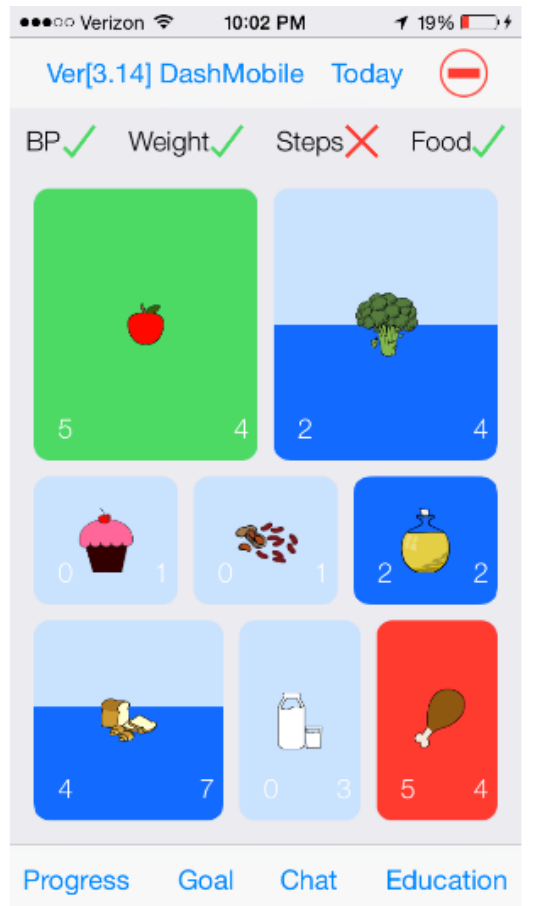

Figure 2. Editable active and achieved goals are listed in the Goals window.

\begin{tabular}{|c|c|c|}
\hline ••voverizon & 10:08 PM & $125 \% \llbracket 4$ \\
\hline <Back & Goals & Edit \\
\hline
\end{tabular}

Walk during lunch break

Cut down on bacon intake

\section{Achieved}

\section{Only eat fast food up to two} times a week

\section{Eat more fruits}


Figure 3. The Chat window, where participants can communicate with their coach.

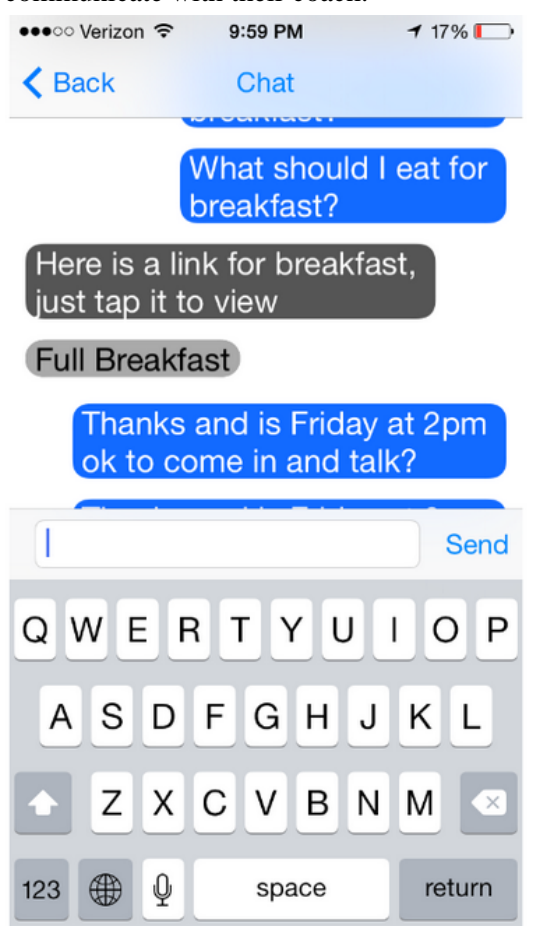

The coach was a master's student trained to use motivational interviewing as a counseling framework to address behavioral health change. Over the course of 13 weeks, the coach interacted with study participants on a weekly basis through a structured, yet flexible, program that consisted of both telephone calls and asynchronous sessions through the communication channel of their preference (instant message, SMS, or email). In addition, over the course of the study, the DASH health coach logged dietary and physical activity data based on assessments made during 6 phone calls during the study period. Based on this data, the DASH coach assisted participants in setting goals for changing behaviors consistent with their hypertension behavior change plan by reviewing collected data with the user, assigning educational tasks, and engaging in problem solving.

\section{Outcomes}

\section{Engagement and Acceptability}

To assess participant acceptability of and engagement with the program, the number of blood pressure measurements, weight measurements, and daily steps were logged. Daily step counts of $\leq 250$ were considered invalid. The number of coaching phone calls attempted and completed, servings documented in the dietary assessment, and goals set were also assessed.

\section{Physiological Parameters}

Blood pressure, heart rate, weight, and steps were collected to assess changes pre- and postintervention. Wireless behavior-tracking devices (blood pressure cuff, scale, and pedometer) were synced via Bluetooth to the mobile app on the participant's smartphone, which uploaded data to the web-based coaching portal.

\section{Statistical Analysis}

Descriptive analyses were performed to summarize the characteristics of our study population. A Wilcoxon signed rank test comparing the first and last documented physiologic measures (blood pressure, heart rate, weight, body mass index, and calories) was performed to assess significant changes post-intervention. The same method was applied to examine changes between the baseline (days 1-7) and follow-up (days 46-120) for the average daily steps. For all tests, $P$ values <.05 were considered statistically significant. Analysis was conducted using SAS 9.4 (SAS Institute).

\section{Results}

\section{Overview}

A total of 17 patients participated in this feasibility pilot study. The mean age of the participants was 59 years (SD 6), and 10/17 $(60 \%)$ were women. The participants in the study had an average baseline BMI of 33.6 (SD 7.46), an average baseline systolic blood pressure of 138.6 (SD 21.47), and average baseline diastolic blood pressure of 86.9 (SD 16.10).

\section{Engagement and Acceptability}

As detailed in Table 1, participants were engaged with the app. All participants logged their weight, steps, and dietary intake and received messages from the coach. Most of the participants $(15 / 17,88 \%)$ utilized the chat feature to send messages to the coach, and 16 participants (94\%) logged their blood pressure and recorded goals. Over 120 days, the mean number of logged measurements per patient was 63 (SD 46) for blood pressure, 52 (SD 45) for weight, and 55 (SD 36) for step counts. Of 102 coaching phone calls, 74 (73\%) were completed. The mean number of food entries per day per patient was 5.9 (SD 4.5), and patients set a mean number of 5 (SD 2) goals. 
Table 1. Engagement measures.

\begin{tabular}{llll}
\hline Engagement measures $^{\mathrm{a}}$ & \multicolumn{2}{l}{ Engagement over study duration } & Engagement per day, mean (SD) \\
& Mean (SD) & Median (IQR) & $14(66)$ \\
\hline Messages sent to the coach per person & $19.3(16.2)$ & $31(74)$ & $0.16(0.14)$ \\
Messages sent from the coach per person & $31.6(16.1)$ & $69(178)$ & $0.26(0.13)$ \\
Number of times blood pressure was logged & $63.1(46.0)$ & $41(76)$ & $0.52(0.38)$ \\
Number of times weight was logged & $51.5(45.1)$ & $63(103)$ & $0.43(0.38)$ \\
Number of times steps were logged & $55.1(35.7)$ & $616(1473)$ & $5.9(4.5)$ \\
Logged food entries & $708.9(541.2)$ & $5.5(5)$ & $\mathrm{N} / \mathrm{A}^{\mathrm{c}}$ \\
Goals recorded & $5.1(1.8)$ & & \\
\hline
\end{tabular}

${ }^{\mathrm{a}}$ Data represented reflect those who used the respective features.

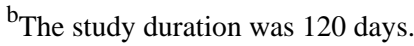

${ }^{\mathrm{c}} \mathrm{N} / \mathrm{A}$ : not applicable.

\section{Physiological Results}

Mean systolic and diastolic blood pressure, heart rate, weight, body mass index, calories, and step counts did not change significantly over time (Multimedia Appendix 1).

\section{Discussion}

\section{Overview}

In this pilot study, we found that an interactive mobile app (DASH Mobile) to promote healthy behaviors that reduce hypertension was feasible and engaged participants. We did not find a difference in physiological outcomes, but we were underpowered to identify such changes.

The average participant routinely logged their blood pressure, weight, steps, food servings and communicated with their DASH Mobile health coach, demonstrating active participation. The engagement findings compare favorably with outcomes for the original web-based implementation of DASH (DASH for Health), which reported only $26 \%$ participation by the end of the 12-month trial in 2008 [5]. More recently, our findings were similar to another web-based implementation of DASH that reported $71 \%$ participation [10].

Mobile interventions are more successful with participant adherence $[6,11,12]$. Adherence promotion can be designed through several approaches including participant-tailored content, providing real time feedback to the participant, and automated or human support to reinforce the behavior change potential of the digital intervention [13-15]. Combining these approaches may increase the effectiveness of an intervention [16]. For example, a recent weight loss study that compared a solely mobile intervention to a mobile intervention blended with in-person components demonstrated that participants in the blended model experienced a greater average weight loss than those who received a purely mobile intervention [16].

We also identified challenges to engagement. Although the Bluetooth-enabled devices were meant to make the experience of collecting physiologic and behavioral data seamless, we experienced difficulties in pairing the devices with the app, resulting in the need to transition to another company's devices. Additionally, scheduling synchronous telephone counseling presented a challenge when the coach's availability did not mesh well with participants' schedules. Like other behavior change programs, motivating participants to read the educational materials remained a challenge. A potential opportunity for improvement could be to tie these closer to the user-facing data visualizations. Finally, while we used line graphs to illustrate data over time, further work should explore patient preferences.

Given the level of engagement in our study, particularly in the area of tracking, a mobile app intervention may be an effective way to integrate and sustain behavior change in hypertension management. Our study did not have enough participants to determine a change in clinical outcome. A power calculation indicates that at least 140 participants would be needed to evaluate the effectiveness of DASH Mobile. Our favorable engagement findings support such a trial. Successful lifestyle change interventions require substantial patient motivation, engagement, and access to experts.

\section{Limitations}

This study is limited in its generalizability, as all participants were required to be English speaking and own a smartphone. Though $77 \%$ of all Americans own a smartphone, only $46 \%$ of Americans aged 65 years or older do [8]. In addition, all measurements were self-administered and thus subject to inaccuracy and bias. Furthermore, the intervention is not autonomous, as it included human-based coaching. However, the incorporation of human-based support is a common feature of effective behavior change programs and does not necessarily preclude dissemination [17-19].

In 2017, the American Heart Association/American College of Cardiology published updated hypertension guidelines [20]. Stage 1 hypertension is now defined as a systolic blood pressure of $130-139 \mathrm{~mm} \mathrm{Hg}$ or a diastolic blood pressure of $80-89 \mathrm{~mm}$ $\mathrm{Hg}$, and Stage 2 hypertension is defined as a systolic blood pressure $\geq 140 \mathrm{~mm} \mathrm{Hg}$ or a diastolic blood pressure $\geq 90 \mathrm{~mm}$ $\mathrm{Hg}$. However, treatment for Stage 1 and Stage 2 hypertension still include the lifestyle changes promoted by DASH. 


\section{Conclusion}

This pilot study demonstrates the feasibility of delivering a digital DASH intervention by leveraging off-the-shelf wireless devices. Participants were engaged, suggesting that a smartphone-based app can be used to deliver behavioral interventions. Future implementations might employ integrated calendars, alarms, social networks, and other smartphone tools to further enhance patient engagement and ultimately clinical outcomes. In summary, our data support the growing interest in using mobile platforms to strengthen user engagement and the accessibility of health behavior change interventions.

\section{Acknowledgments}

This study was sponsored through a grant (9090010602) from the Center for Integration of Medicine and Innovative Technology (CIMIT). Bluetooth devices were provided by iHealth Labs. HW was supported by the NYU CTSA grant from the National Center for Advancing Translational Sciences, National Institutes of Health (KL2TR001446) and is currently supported by a grant from the National Heart, Lung, and Blood Institute, National Institutes of Health (K23HL145110).

\section{Conflicts of Interest}

None declared.

\section{Multimedia Appendix 1}

Change in physiological outcomes from baseline to follow-up.

[DOCX File, 16 KB-Multimedia Appendix 1]

\section{References}

1. Benjamin E, Blaha M, Chiuve S, Cushman M, Das SR, Deo R, American Heart Association Statistics Committee Stroke Statistics Subcommittee. Heart Disease and Stroke Statistics-2017 Update: A Report From the American Heart Association. Circulation 2017 Mar 07;135(10):e146-e603 [FREE Full text] [doi: 10.1161/CIR.0000000000000485] [Medline: 28122885]

2. Merai R, Siegel C, Rakotz M, Basch P, Wright J, Wong B, DHSc, et al. CDC Grand Rounds: A Public Health Approach to Detect and Control Hypertension. MMWR Morb Mortal Wkly Rep 2016 Nov 18;65(45):1261-1264 [FREE Full text] [doi: 10.15585/mmwr.mm6545a3] [Medline: 27855138]

3. Appel LJ, Moore TJ, Obarzanek E, Vollmer WM, Svetkey LP, Sacks FM, et al. A Clinical Trial of the Effects of Dietary Patterns on Blood Pressure. N Engl J Med 1997 Apr 17;336(16):1117-1124. [doi: 10.1056/nejm199704173361601]

4. Kwan MW, Wong MC, Wang HH, Liu KQ, Lee CL, Yan BP, et al. Compliance with the Dietary Approaches to Stop Hypertension (DASH) diet: a systematic review. PLoS One 2013 Oct 30;8(10):e78412 [FREE Full text] [doi: 10.1371/journal.pone.0078412] [Medline: 24205227]

5. Moore TJ, Alsabeeh N, Apovian CM, Murphy MC, Coffman GA, Cullum-Dugan D, et al. Weight, blood pressure, and dietary benefits after 12 months of a web-based nutrition education program (DASH for health): longitudinal observational study. J Med Internet Res 2008 Dec 12;10(4):e52 [FREE Full text] [doi: 10.2196/jmir.1114] [Medline: 19073541]

6. Bennett GG, Glasgow RE. The delivery of public health interventions via the Internet: actualizing their potential. Annu Rev Public Health 2009 Apr;30(1):273-292. [doi: 10.1146/annurev.publhealth.031308.100235] [Medline: 19296777]

7. Toro-Ramos T, Kim Y, Wood M, Rajda J, Niejadlik K, Honcz J, et al. Efficacy of a mobile hypertension prevention delivery platform with human coaching. J Hum Hypertens 2017 Dec 3;31(12):795-800. [doi: 10.1038/jhh.2017.69] [Medline: 28972573]

8. Pew Research Center. Mobile Fact Sheet URL: http://www.pewinternet.org/fact-sheet/mobile/\# [accessed 2019-02-21]

9. Mann DM, Quintiliani LM, Reddy S, Kitos NR, Weng M. Dietary Approaches to Stop Hypertension: Lessons Learned From a Case Study on the Development of an mHealth Behavior Change System. JMIR mHealth uHealth 2014 Oct 23;2(4):e41 [FREE Full text] [doi: 10.2196/mhealth.3307] [Medline: 25340979]

10. Staffileno BA, Tangney CC, Fogg L. Favorable Outcomes Using an eHealth Approach to Promote Physical Activity and Nutrition Among Young African American Women. The Journal of Cardiovascular Nursing 2018;33(1):62-71. [doi: 10.1097/jcn.0000000000000409]

11. Pham Q, Graham G, Carrion C, Morita PP, Seto E, Stinson JN, et al. A Library of Analytic Indicators to Evaluate Effective Engagement with Consumer mHealth Apps for Chronic Conditions: Scoping Review. JMIR mHealth uHealth 2019 Jan 18;7(1):e11941 [FREE Full text] [doi: 10.2196/11941] [Medline: 30664463]

12. Oh B, Yi G, Han MK, Kim JS, Lee CH, Cho B, et al. Importance of Active Participation in Obesity Management Through Mobile Health Care Programs: Substudy of a Randomized Controlled Trial. JMIR mHealth uHealth 2018 Jan 03;6(1):e2 [FREE Full text] [doi: 10.2196/mhealth.8719] [Medline: 29298749]

13. Ritterband LM, Thorndike FP, Cox DJ, Kovatchev BP, Gonder-Frederick LA. A behavior change model for internet interventions. Ann Behav Med 2009 Aug 4;38(1):18-27 [FREE Full text] [doi: 10.1007/s12160-009-9133-4] [Medline: 19802647] 
14. Bernecker SL, Banschback K, Santorelli GD, Constantino MJ. A Web-Disseminated Self-Help and Peer Support Program Could Fill Gaps in Mental Health Care: Lessons From a Consumer Survey. JMIR Ment Health 2017 Jan 19;4(1):e5 [FREE Full text] [doi: 10.2196/mental.4751] [Medline: 28104578]

15. Piette JD, List J, Rana GK, Townsend W, Striplin D, Heisler M. Mobile Health Devices as Tools for Worldwide Cardiovascular Risk Reduction and Disease Management. Circulation 2015 Nov 24;132(21):2012-2027. [doi: 10.1161/circulationaha.114.008723]

16. Hurkmans E, Matthys C, Bogaerts A, Scheys L, Devloo K, Seghers J. Face-to-Face Versus Mobile Versus Blended Weight Loss Program: Randomized Clinical Trial. JMIR mHealth uHealth 2018 Jan 11;6(1):e14. [doi: 10.2196/mhealth.7713]

17. Asbjørnsen RA, Smedsrød ML, Solberg Nes L, Wentzel J, Varsi C, Hjelmesæth J, et al. Persuasive System Design Principles and Behavior Change Techniques to Stimulate Motivation and Adherence in Electronic Health Interventions to Support Weight Loss Maintenance: Scoping Review. J Med Internet Res 2019 Jun 21;21(6):e14265 [FREE Full text] [doi: 10.2196/14265] [Medline: 31228174$]$

18. Kim SE, Castro Sweet CM, Cho E, Tsai J, Cousineau MR. Evaluation of a Digital Diabetes Prevention Program Adapted for Low-Income Patients, 2016-2018. Prev Chronic Dis 2019 Nov 27;16:E155 [FREE Full text] [doi: 10.5888/pcd16.190156] [Medline: $\underline{31775010}$ ]

19. Michaelides A, Major J, Pienkosz E, Wood M, Kim Y, Toro-Ramos T. Usefulness of a Novel Mobile Diabetes Prevention Program Delivery Platform With Human Coaching: 65-Week Observational Follow-Up. JMIR mHealth uHealth 2018 May 03;6(5):e93 [FREE Full text] [doi: 10.2196/mhealth.9161] [Medline: 29724709]

20. Whelton P, Carey R, Aronow W. ACC/AHA/AAPA/ABC/ACPM/AGS/APhA/ASH/ASPC/NMA/PCNA Guideline for the Prevention, Detection, Evaluation, and Management of High Blood Pressure in Adults: A Report of the American College of Cardiology/American Heart Association. Task Force on Clinical Practical Guidelines. Hypertension 2018 Feb 26;7(1):68-74. [doi: 10.1016/j.jacc.2017.11.006]

\title{
Abbreviations
}

DASH: Dietary Approaches to Stopping Hypertension

\author{
Edited by G Eysenbach; submitted 12.03.19; peer-reviewed by S Persell, $S$ Weinland, RK B, OB Kristjansdottir, C Fernández-Lao, \\ E Sezgin; comments to author 31.10.19; revised version received 23.12.19; accepted 22.03.20; published 07.05.20 \\ Please cite as: \\ Weerahandi H, Paul S, Quintiliani LM, Chokshi S, Mann DM \\ A Mobile Health Coaching Intervention for Controlling Hypertension: Single-Arm Pilot Pre-Post Study \\ JMIR Form Res 2020;4(5):e13989 \\ URL: http://formative.jmir.org/2020/5/e13989/ \\ doi: $\underline{10.2196 / 13989}$ \\ PMID: 32379049
}

CHimali Weerahandi, Soaptarshi Paul, Lisa M Quintiliani, Sara Chokshi, Devin M Mann. Originally published in JMIR Formative Research (http://formative.jmir.org), 07.05.2020. This is an open-access article distributed under the terms of the Creative Commons Attribution License (https://creativecommons.org/licenses/by/4.0/), which permits unrestricted use, distribution, and reproduction in any medium, provided the original work, first published in JMIR Formative Research, is properly cited. The complete bibliographic information, a link to the original publication on http://formative.jmir.org, as well as this copyright and license information must be included. 